\title{
Cequestáo
}

\section{Padrão de colaboração e coautoria no campo de turismo: análises bibliométricas e de redes em 14 periódicos científicos brasileiros (1990-2016)}

\author{
André Fontan Köhler \\ Doutor; Universidade de São Paulo, São Paulo, SP, Brasil; \\ afontan@usp.br \\ Luciano Antonio Digiampietri \\ Doutor; Universidade de São Paulo, São Paulo, SP, Brasil; \\ digiampietri@usp.br \\ Gabriela Sarro de Almeida \\ Bacharel; Universidade de São Paulo, São Paulo, SP, Brasil; \\ gabriela.sarro.almeida@usp.br
}

Resumo: Neste trabalho, são analisados os artigos publicados em 14 periódicos brasileiros de turismo (de 1990 a 2016). Os objetivos são identificar os padrões de coautoria e verificar a importância de atores para a rede. A metodologia consiste em análise bibliométrica e de redes sociais. As redes de autores e instituições são robustas, não dependendo de um ator central. O campo é marcado pela grande fragmentação, sem uma abordagem teórica unificada. As redes de autores e instituições são formadas por um grupo central - com os nós mais importantes e produtivos - e uma "periferia", composta por pequenos grupos com baixa produção.

Palavras-chave: Turismo. Periódicos científicos. Análise bibliométrica e de redes sociais.

\section{Introdução}

Tribe (1997) aponta que há três dimensões do turismo. Primeiro, há o fenômeno do turismo ou mundo externo do turismo, que consiste na soma de fenômenos e relações derivadas da interação entre turistas, residentes locais, governos, ambientes e negócios turísticos. Segundo, há a educação e o treinamento em turismo, cujos elementos mais visíveis são os cursos técnicos e os cursos de bacharelado em turismo. Por fim, há a dimensão "estudo do turismo", representada por uma comunidade acadêmica voltada à pesquisa, que resulta em 


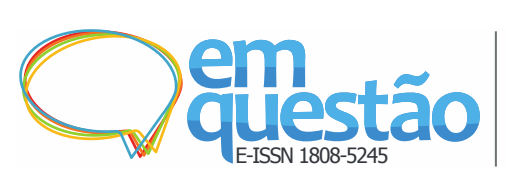

Padrão de colaboração e coautoria no campo de turismo: análises bibliométricas e de redes em 14 periódicos científicos brasileiros (1990-2016)

André Fontan Köhler, Luciano Antonio Digiampietri e Gabriela Sarro de Almeida

um crescente corpo de conhecimento específico sobre turismo.

O turismo não forma uma ciência, nem sequer uma disciplina específica, mas sim um campo de conhecimento, que se divide nos seguintes subcampos: (a) administração/gestão e negócios turísticos; e (b) ciências sociais e turismo (BENCKENDORFF; ZEHRER, 2013; TRIBE, 1997, 2010).

Benckendorff e Zehrer (2013) caracterizam o turismo como um campo de conhecimento fragmentado e interdisciplinar, que não conta com uma abordagem teórica unificada, mas sim múltiplas, derivadas e advindas do conjunto de ciências e disciplinas que trabalham e estudam o fenômeno do turismo.

Ao estudarem as referências bibliográficas dos artigos publicados nas revistas Tourism Management, Annals of Tourism Research e Journal of Travel Research, no período 1996-2010, Benckendorff e Zehrer (2013) concluem, tomando como base a citação conjunta de trabalhos, que o campo do turismo pode ser dividido nos seguintes segmentos: (a) temas de sociologia, antropologia e psicologia / turismo como fenômeno social / turistas; (b) abordagem geográfica e de planejamento / planejamento turístico e percepções dos residentes locais / oferta turística e planejamento do destino; e (c) comportamento do consumidor / comportamento do consumidor e avaliações dos turistas acerca de destinos turísticos / marketing e imagem do destino.

A crescente competição por recursos públicos tem levado a várias tentativas de se medir a quantidade, qualidade e excelência da pesquisa científica de autores, instituições, países e periódicos, o que acarretou no surgimento de inúmeros métodos e métricas de avaliação e classificação (PAGE, 2005).

No Brasil, o periódico científico há mais tempo em publicação no campo de turismo, é o Turismo em Análise, que, no período 1990-2016, publicou 556 artigos. Dado que a coleta de dados foi realizada em 2017, ela contemplou os artigos publicados de 1990, ano de início do periódico Turismo em Análise, até o ano imediatamente anterior (2016). O segundo mais antigo, ainda em publicação, é a Revista Turismo - Visão e Ação, que já conta com 384 artigos (1998-2016). Atualmente, o campo do Turismo tem mais de 20 periódicos, que, 
às vezes, conjugam-se com outras áreas, a exemplo de Administração, Marketing e Economia. A maior parte deles é classificada no Qualis Capes.

Apesar da interrupção de algumas revistas, a trajetória dos periódicos científicos brasileiros aponta o crescimento do campo de Turismo. Tem havido aumento no número de títulos e de artigos anualmente publicados e uma boa e crescente avaliação de vários periódicos no Qualis Capes, com destaque para a Revista Brasileira de Pesquisa em Turismo (A2), Revista Turismo - Visão e Ação (B1), Revista Turismo em Análise (B1) e Caderno Virtual de Turismo (B1) $)^{1}$

A bibliometria é o estudo dos aspectos quantitativos da produção, circulação e utilização da informação. Ela permite a avaliação e o monitoramento da produção científica de uma ciência, disciplina ou campo de conhecimento, por meio das citações, referências bibliográficas, palavras-chave, métodos de pesquisa utilizados etc. (HOOD; WILSON, 2001; KOSEOGLU et al., 2016; WANG; CHAI, 2018). Já a análise de redes sociais permite a compreensão dos padrões de comunicação e interação entre integrantes de uma ciência, disciplina ou campo de conhecimento, possibilitando a análise, dentre outras coisas, da estrutura da rede como um todo e de seus subgrupos, de atoreschave para a produção e disseminação de conhecimento e da trajetória da rede (RACHERLA; HU, 2010).

\section{Objeto de estudo, justificativa e objetivos de pesquisa}

O objeto de estudo é o conjunto de artigos publicados em periódicos científicos brasileiros, que cumprem quatro pré-requisitos. Primeiro, em 01 de junho de 2017, a revista já precisava ter lançado todos os números do ano imediatamente anterior (2016), sendo considerada, assim, ativa. Segundo, ela precisa ter sido avaliada, no Qualis Capes (quadriênio 2013-2016), como pelo menos B5 para a área "Administração pública e de empresas, ciências contábeis e turismo", o que mostra sua relevância para a pós-graduação stricto sensu dessa área.

Terceiro, o periódico precisa ter um sistema de dupla avaliação cega por pares, ponto básico para garantir a idoneidade e qualidade de o que é publicado. 
Quarto, ele precisa ser de Turismo, mas não conjugado a outra área (Administração, Marketing, Economia etc.); isso evita que o estudo considere artigos que não versem sobre turismo.

A Tabela 1 lista os 14 periódicos nacionais que cumprem todos esses pré-requisitos, junto com a quantidade de artigos publicados, total e por década (anos 1990, 2000 e 2010), para cada um deles.

Tabela 1 - Periódicos científicos e quantidade de artigos publicados

Título do periódico 1990-1999 2000-2009 2010-2016

\begin{tabular}{lrrrr}
\hline Anais Brasileiros de Estudos Turísticos & 0 & 0 & 95 & $\mathbf{9 5}$ \\
\hline C. de Estudos e Pesquisas do Turismo & 0 & 0 & 66 & $\mathbf{6 6}$ \\
\hline Caderno Virtual de Turismo & 0 & 207 & 202 & $\mathbf{4 0 9}$ \\
\hline R. A. Observatório de Inovação do Turismo & 0 & 78 & 91 & $\mathbf{1 6 9}$ \\
\hline Revista Brasileira de Ecoturismo & 0 & 15 & 266 & $\mathbf{2 8 1}$ \\
\hline Revista Brasileira de Pesquisa em Turismo & 0 & 44 & 173 & $\mathbf{2 1 7}$ \\
\hline Revista Iberoamericana de Turismo & 0 & 0 & 136 & $\mathbf{1 3 6}$ \\
\hline Revista de Turismo Contemporâneo & 0 & 0 & 61 & $\mathbf{6 1}$ \\
\hline Revista Latino-Americana de Turismologia & 0 & 0 & 24 & $\mathbf{2 4}$ \\
\hline Revista Turismo e Sociedade & 0 & 21 & 174 & $\mathbf{1 9 5}$ \\
\hline Revista Turismo em Análise & 159 & 178 & 219 & $\mathbf{5 5 6}$ \\
\hline Revista Turismo: Estudos e Práticas & 0 & 0 & 79 & $\mathbf{7 9}$ \\
\hline Revista Turismo - Visão e Ação & 22 & 186 & 176 & $\mathbf{3 8 4}$ \\
\hline Rosa dos Ventos & 0 & 5 & 216 & $\mathbf{2 2 1}$ \\
\hline TOTAL & $\mathbf{1 8 1}$ & $\mathbf{7 3 4}$ & $\mathbf{1 9 7 8}$ & $\mathbf{2 8 9 3}$ \\
\hline
\end{tabular}

Fonte: Elaborado pelos autores.

Seguindo-se a maior parte dos estudos bibliométricos e de redes no turismo, avalia-se que os artigos publicados em periódicos são o tipo de produção científica mais importante para a compreensão do campo de conhecimento, bem como para a avaliação da qualidade de uma pesquisa, pesquisador, instituição ou mesmo país (BENCKENDORFF; ZEHRER, 2013; MCKERCHER, 2005).

A pesquisa justifica-se por três pontos principais. Primeiro, ainda há certa escassez de estudos bibliométricos e de redes sobre a produção científica brasileira em Turismo; isso é particularmente observável no caso de redes de coautoria e colaboração. Apesar de Santos, Panosso Netto e Wang (2017) e Santos e Rejowski (2013) trazerem amplas análises sobre a produção nacional, ainda não há um trabalho que contemple as redes de colaboração e coautoria do campo, como esse estudo faz. Além disso, o artigo contempla o período 1990- 
2016, e traz uma série de métricas e redes ainda não analisadas para os periódicos nacionais de Turismo.

Segundo, os periódicos brasileiros têm uma trajetória de quase três décadas, marcada, de um lado, pelo aumento da produção anual de artigos e diversificação de títulos e, de outro, por mudanças profundas no próprio campo, como, por exemplo, a abertura e consolidação de vários programas de pósgraduação stricto sensu e a criação da Associação Nacional de Pesquisa e PósGraduação em Turismo (ANPTUR).

Terceiro, ao contrário de o que ocorria até os anos 2000, o campo de turismo brasileiro não é "impermeável” à produção nacional. De um lado, muitos autores vinculados a instituições estrangeiras têm publicado em periódicos científicos brasileiros, nos últimos anos. Do outro, muitos autores brasileiros têm conseguido publicar em periódicos internacionais, com destaque para os de língua espanhola e inglesa. Indicativo disso é o fato de que, dos 22 autores presentes na Tabela 8, 18 tenham publicado em periódicos internacionais, principalmente nos últimos anos.

$\mathrm{O}$ artigo apresenta dois objetivos principais. O primeiro é identificar os padrões de colaboração e coautoria entre autores, instituições e países no campo de turismo, no período 1990-2016, por meio da análise dos 14 periódicos selecionados. A análise e avaliação recaem não apenas sobre o período inteiro, mas também sobre sua trajetória, a fim de verificar o amadurecimento do campo. O segundo é identificar e verificar a importância e centralidade de atores (autores, instituições e países) dentro da rede de coautoria e colaboração, no que tange à importância do ator para o fluxo de informações e a realização de parcerias.

Além desses objetivos gerais, o artigo também apresenta e discute alguns dados básicos acerca da autoria dos artigos - como, por exemplo, a trajetória da média, moda e mediana do número de autores, instituições e países por artigo e do adensamento da rede de colaboração e coautoria, por meio da adição de novos atores, ano a ano. 


\section{Metodologia de pesquisa}

Como é de praxe nos estudos bibliométricos e de redes, que têm por objeto periódicos (BENCKENDORFF; ZEHRER, 2013; JOGARATNAM et al., 2005; SANTOS; PANOSSO NETTO; WANG, 2017; ZHAO; RITCHIE, 2007), a pesquisa contempla apenas artigos, excluindo editoriais, resenhas, entrevistas e demais materiais.

Ao contrário dos trabalhos consultados, optou-se pela coleta manual de dados - autores, instituições e países das instituições - de todos os 2.893 artigos. Isso se deve, principalmente, à ausência de bancos de dados confiáveis que reúnam esses elementos, ao contrário de o que se verifica com os principais periódicos internacionais de Turismo. Além disso, a coleta manual permitiu a verificação, correção e desambiguação dos nomes.

Foram feitos três processos de verificação, correção e desambiguação dos nomes, tendo sido os dois primeiros manuais. Em cada processo, houve a participação de um professor doutor e de um assistente de pesquisa (nível graduação). Foram feitas mais de 2.000 correções e desambiguações, principalmente para autores e instituições. Alguns autores apareciam com mais de cinco variações do próprio nome, devido à supressão e abreviação de sobrenomes.

A consulta à Plataforma Lattes e a sítios eletrônicos de instituições e programas de graduação e pós-graduação, apesar de demorada, ajudou a tornar os dados ainda mais confiáveis. Na terceira e última verificação, foram feitas apenas três correções.

Com a formação da base de dados, foi utilizada a metodologia proposta por Digiampietri et al. (2014) para a limpeza dos dados e resolução de nomes (terceira verificação $)^{2}$, construção de redes sociais de coautoria e cálculo de métricas. A primeira é uma análise bibliométrica, que levantou uma série de dados básicos, como, por exemplo, a média, moda e mediana da quantidade de artigos publicados por autor (período total e trajetória).

A segunda é uma análise de redes sociais, feita por meio da caracterização das redes através de vários tipos de métricas (assortatividade, 
centralidade, centralização etc.) e do cálculo e construção das redes (grafos) de coautoria. Para a presente pesquisa, foram calculadas 19 métricas, seguindo-se Wasserman e Faust (2009). Para a montagem das redes, utilizou-se a teoria dos grafos. Nela, cada ator - seja autor, instituição ou país - é representado por um nó, e cada relação entre atores - nesse caso, de coautoria - é representada por uma aresta.

Para fins de visualização, optou-se, nesse trabalho, por apresentar os nós com tamanho proporcional ao número de relacionamentos, ao passo que as arestas têm igual grossura, não refletindo o número de artigos que está por trás de cada relação de coautoria. Por questão de restrições ao tamanho do artigo, apresentam-se apenas os dados, métricas e redes dos autores, das primeiras instituições dos autores e de seus respectivos países ${ }^{3}$.

\section{Revisão de literatura - estudos bibliométricos e de redes}

Os estudos bibliométricos e de redes buscam prover indicadores de impacto, produtividade e centralidade para atores e periódicos, compreender o turismo como um sistema de criação e disseminação de conhecimento, e gerar informações para que discentes, pesquisadores e dirigentes de instituições possam ter um melhor embasamento para tomar decisões.

A depender dos dados coletados e dos objetivos da pesquisa, esses estudos prestam-se a responder uma ou mais das seguintes perguntas: (a) qual é a estrutura intelectual do campo e sua trajetória?; (b) qual é a estrutura social do campo e sua trajetória?; (c) quais são as estruturas conceituais do campo e sua trajetória?; (d) como se deve avaliar a produção científica do campo?; (e) como medir e avaliar o impacto da pesquisa dos atores do campo?; e (f) quais são os temas, métodos de pesquisa e casos mais presentes no campo e sua trajetória? (BENCKENDORFF; ZEHRER, 2013; KOSEOGLU et al., 2016).

Há uma série de métricas para auxiliar na compreensão e avaliação do campo de Turismo e do papel e importância de seus atores. Na literatura, já se reconhece que não há uma única métrica estritamente superior a todas as outras. Independentemente da agenda de pesquisa e de seus objetivos, é importante 
calcular e analisar um conjunto de métricas, seja para a avaliação de um periódico científico ou para a compreensão do padrão de colaboração e coautoria do campo como um todo (HALL, 2011; MCKERCHER, 2005).

No campo de Turismo, Koseoglu et al. (2016) apontam que os estudos subdividem-se em três grandes grupos. Primeiro, há os trabalhos de revisão (review studies), que combinam estatística básica com uma análise qualitativa, a fim de descrever o campo - ou parte dele - e sua trajetória. Segundo os autores, os trabalhos de revisão podem ser de seis tipos, a saber: (a) focado em disciplina (discipline-focused): trata-se do esforço de classificar um conjunto de artigos segundo temas, áreas e/ou assuntos; (b) focado em tema (theme-focused): trabalhos que discutem a trajetória de um ou mais temas, como, por exemplo, o Turismo Cultural, dentro do campo; (c) focado em metodologia (methodology/method/statistics-focused): é o caso do trabalho de Kovacs et al. (2012), que, tomando como objeto todos os artigos publicados nos anais da ANPTUR, no período 2006-2008, verificou a metodologia de pesquisa utilizada em cada um deles; (d) focado em amostra (sample-focused): estudos que se centram em artigos selecionados devido a seu objeto e amostra de pesquisa (setor, tipo de turista, região etc.); (e) focado em ator (contributor-focused): trabalhos que apontam os autores, instituições, países e/ou periódicos mais importantes do campo; e (f) focado em periódico (journal-focused): trabalhos que analisam a trajetória de uma revista (KOSEOGLU et al., 2016).

Segundo, há as técnicas avaliativas (evaluative techniques), que buscam medir o desempenho de um artigo, autor, instituição, país ou periódico. Segundo Hall (2011), isso é feito utilizando três grupos de métricas. As métricas de produtividade incluem pontos como número de artigos citados, número de artigos por ano acadêmico, número de artigos por pesquisador etc.

As métricas de impacto incluem número total de citações, número de citações por ano acadêmico, número de citações por determinado autor ou revista etc. Por fim, as métricas híbridas incluem o número médio de citações por artigo e medidas como, por exemplo, o índice $\mathrm{h}$ e o quociente $\mathrm{m}$ (BENCKENDORFF; ZEHRER, 2013; HALL, 2011; KOSEOGLU et al., 2016). 


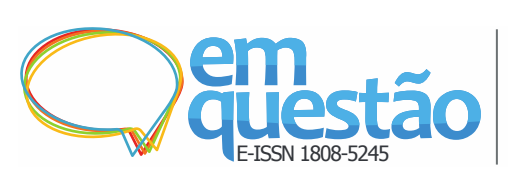

Padrão de colaboração e coautoria no campo de turismo: análises bibliométricas e de redes em 14 periódicos científicos brasileiros (1990-2016)

André Fontan Köhler, Luciano Antonio Digiampietri e Gabriela Sarro de Almeida

Terceiro, há as técnicas relacionais (relational techniques), que, apesar de ainda raras no campo de Turismo, já são relativamente comuns na Administração. Elas exploram as relações existentes entre os dados de um artigo, e podem ser de quatro tipos. A análise de co-citação (co-citation analysis) é utilizada para se avaliar a estrutura intelectual do campo, a partir das referências bibliográficas dos artigos publicados. No Brasil, Santos, Panosso Netto e Wang (2017) contemplam uma análise de co-citação, tendo como objeto quatro periódicos brasileiros de Turismo.

O acoplamento bibliográfico (bibliographic coupling) utiliza o número de referências bibliográficas compartilhadas por dois ou mais artigos como uma medida de similaridade entre eles. A análise de coautoria (co-author analysis) é utilizada para se avaliar o padrão de colaboração e coautoria de um campo, mostrando a disposição e a organização de seus grupos.

Já a análise de coocorrência de palavras (co-word analysis): “[...] é uma técnica de análise de conteúdo, que utiliza as palavras dos documentos para estabelecer relações e construir uma estrutura conceitual do domínio (Callon, Turner, \& Bauin, 1983).” (KOSEOGLU et al., 2016, p. 183, tradução nossa).

A presente pesquisa utiliza um conjunto de métodos, métricas e análises de redes desses três grandes grupos, com o intuito de melhor caracterizar e compreender o padrão de colaboração e coautoria do campo de Turismo no Brasil. Contudo, dados os objetivos da pesquisa, destacam-se as métricas e análises das técnicas avaliativas e relacionais, como está claro no próximo item.

\section{Revisão de literatura - conceitos, medidas e métricas}

Foi utilizado um amplo e variado conjunto de métricas, medidas e análises de redes, de modo que se pudesse ter uma avaliação clara do campo de Turismo no Brasil, a partir dos objetivos deste trabalho. Salvo indicado, o cálculo sempre é apresentado para autores, instituições e países.

Um componente conexo de uma rede é um subgrupo no qual todos os nós estão interconectados, direta ou indiretamente, entre si por um caminho de arestas. O componente conexo com a maior quantidade de nós de uma rede é 
denominado de componente gigante. Por definição, isso não significa que ele tenha a maior quantidade de artigos publicados, dado que os nós representam os atores, e não os trabalhos em si (WASSERMAN; FAUST, 2009).

A primeira medida calculada é a quantidade de artigos publicados, por ator; mostram-se a distribuição dos atores, por número de artigos, e a média, moda e mediana. Jogaratnam et al. (2005) apontam, corroborando outras pesquisas, que a maior parte dos autores publica apenas um artigo, e que poucos têm sete ou mais artigos publicados.

A segunda é a quantidade de colaboradores, por ator; mostram-se a distribuição e a média, moda e mediana. A colaboração é a coautoria entre dois atores, independentemente do número de trabalhos resultante dessa colaboração.

A adição de novos atores à rede mostra a entrada de novos autores, instituições e países no campo de turismo, tanto de forma geral quanto para aqueles que publicaram mais de um artigo.

Para se medir a concentração e distribuição da produção do campo, e se verificar o peso dos atores mais produtivos, apresenta-se, também, o quanto os primeiros centil (1\%), decil (10\%) e quartil (25\%) representam do total.

A análise de redes sociais é uma técnica que permite o mapeamento, a análise e a avaliação de relações - neste trabalho, a coautoria de artigos publicados em periódicos - entre atores (RACHERLA; HU, 2010).

$\mathrm{Na}$ análise de redes sociais, o foco é no padrão de colaboração e interação entre os atores da rede, e não nas características de atores individuais. Para tal, calcularam-se 19 métricas, junto com a montagem e apresentação de redes.

O grau de um nó mostra o número de arestas (coautorias) conectadas a ele. Para a rede, tem-se o grau médio, que aponta o nível de capilaridade e interconexão dos nós da rede (SZWARCFITER, 1986).

O caminho (path) é igual ao número de arestas necessárias para se sair de um nó, e chegar em outro; trata-se, portanto, de uma medida local. O caminho mínimo (caminho geodésico) é o caminho que passa pelo menor número de arestas entre dois nós, sendo também uma medida local. A partir 
dela, calcula-se a média dos caminhos geodésicos para a rede, que aponta sua extensão e seu nível de capilaridade (WASSERMAN; FAUST, 2009).

A porcentagem de nós no componente gigante mostra a porcentagem de elementos que fazem parte do maior componente conexo. Avalia-se que pertencer ao componente gigante faz o nó participar do principal fluxo de conhecimento e informação da rede. Quanto maior for a porcentagem, mais os atores estão interconectados, o que é indicativo de maior maturidade do campo.

O diâmetro de um grafo é o maior caminho geodésico da rede (NEWMAN, 2003). Ou seja, é a maior distância que se pode encontrar entre dois nós em toda a rede, a partir de seu caminho mínimo. A métrica é útil para a efetiva medição de o quão separados os elementos mais distantes de uma rede estão. Se imaginarmos que as informações são propagadas por meio de pessoas relacionadas, então o diâmetro pode ser utilizado para inferir a quantidade de tempo necessária para a propagação de informações na rede entre seus membros mais distantes.

A densidade de uma rede é igual à razão entre o número de arestas existentes e o número máximo de arestas possível (todos os nós interconectamse diretamente a todos os outros) (SCOTT, 2009).

A clique é um subgrupo de um componente conexo, no qual todos os nós estão diretamente interconectados por arestas. O coeficiente de aglomeração ou coeficiente de clusterização mede a transitividade das interconexões de uma rede. Ele é calculado dividindo-se a quantidade de cliques de tamanho três pela quantidade de trios de nós que possuem, pelo menos, um caminho com duas arestas que os conectem. Esta métrica é fundamental para se medir a estabilidade e a maturidade do campo de conhecimento (SCOTT, 2009; LEMIEUX; OUIMET, 2008).

As métricas de assortatividade medem a tendência da existência de arestas entre nós que compartilhem determinada característica. Nesta pesquisa, foram calculadas a assortatividade de grau e a assortatividade de instituição (essa última apenas para autores). Essas métricas variam de -1 (apenas nós que não compartilhem a característica estão interconectados) a 1 (apenas nós que compartilhem a característica estão interconectados). 
As medidas de centralidade refletem a importância de um determinado nó na rede - o quão central ele é. Ou seja, o quanto as colaborações de um ator o tornam visível e um importante ponto de conexão dentro da rede. Aqui, calculam-se três métricas de centralidade, mostrando os dez autores, cinco instituições e três países com as maiores centralidades.

A centralidade de grau reflete o grau do nó, ou seja, quantas conexões ele tem com seus vizinhos de rede (número de arestas). A centralidade de proximidade (closeness) reflete a distância entre o nó analisado e todos os demais nós da rede, a partir de seus caminhos mínimos. Já a centralidade de intermediação (betweeness) reflete, para um determinado nó, a frequência com a qual ele aparece entre todos os caminhos mínimos existentes na rede, para todos os pares de nós. Os nós que aparecem em muitos caminhos mínimos são considerados centrais, dado que tendem a controlar o fluxo de informação da rede (RACHERLA; HU, 2010). Para as três métricas de centralidade listadas, quanto maior o número, mais central - e importante - é o nó em questão.

As medidas de centralização ou centralidade de rede baseiam-se nas métricas de centralidade, e refletem a importância que o nó mais central tem para a rede. Uma rede com alta centralização mostra que há um elemento muito central (importante), o que a torna muito dependente dele (WASSERMAN; FAUST, 2009).

Quanto maior for a centralização, mais frágil a rede é, pois depende muito de um nó central. Seguindo a mesma lógica das centralidades, são calculadas três métricas de centralização - de grau, de proximidade e de intermediação.

O trabalho apresenta três redes (autores, instituições e países), nas quais é possível visualizar todos os nós e arestas existentes.

\section{Resultados - apresentação e discussão}

Os 14 periódicos selecionados publicaram 2.893 artigos no período 1990-2016, com 3.715 autores, 804 instituições e 38 países únicos. 
Esta seção traz, em bloco, todas as tabelas e figuras com os resultados, para, só depois, proceder à análise e discussão da estrutura, trajetória e padrão de colaboração e coautoria. Isso se dá pelo fato de alguns pontos, a exemplo do nível de estabilidade e maturidade do campo, demandarem um conjunto de métricas e redes, e não apenas um indicador, para sua análise e discussão.

A Tabela 2 traz a adição de novos atores à rede, tanto geral (“Adição") quanto para os que publicaram mais de um artigo (“Adição [>1]"). A Tabela 3 mostra a distribuição dos atores, por número de artigos publicados.

A Tabela 4 traz a distribuição dos atores, por número de colaborações. Frisa-se que a coautoria entre dois atores, na publicação, conta sempre como uma colaboração, independentemente do número de artigos gerados pela parceria. A Tabela 5 expõe a concentração da produção de artigos, nos primeiros centil (1\%), decil (10\%) e quartil (25\%) mais produtivos. O critério de classificação considerou a adição de "novos" artigos (ainda não contabilizados). Para o desempate, utilizou-se o número de artigos do ator (já contabilizados ou não).

A Tabela 6 mostra a média, mediana e moda do número de artigos publicados e da quantidade de colaborações, por ator, de forma cumulativa. A Tabela 7 traz as métricas globais das redes, também apresentadas cumulativamente.

A Tabela 8 traz a lista dos 42 atores que, em pelo menos uma das métricas de centralidade, aparecem entre os dez primeiros autores, as cinco primeiras instituições ou os três primeiros países. Junto com o valor de cada centralidade, há a classificação do ator. As duas últimas colunas trazem o número de artigos publicados pelo ator e sua classificação.

Após as tabelas, o artigo apresenta as redes de autores (Figura 1), instituições (Figura 2) e países (Figura 3), no período 1990-2016. Não foram colocados os rótulos para identificar os atores, pois isso dificultaria sobremaneira sua leitura, e pelo fato de os grafos serem importantes para a análise do padrão de colaboração da rede como um todo, e não para verificar posições individuais. 
Padrão de colaboração e coautoria no campo de turismo: análises bibliométricas e de redes em 14 periódicos científicos brasileiros (1990-2016)

André Fontan Köhler, Luciano Antonio Digiampietri e Gabriela Sarro de Almeida

Tabela 2 - Adição de novos atores à rede

\begin{tabular}{lrrrrrrr}
\multirow{2}{*}{ Período } & \multicolumn{2}{c}{ Autores } & \multicolumn{2}{c}{ Instituiçães } & \multicolumn{2}{c}{ Países } \\
\cline { 2 - 8 } & Adição & Adição [>1] & Adição & Adição [>1] & Adição & Adição [>1] \\
\hline 1990 & 12 & 9 & 3 & 2 & 2 & 2 \\
\hline $1991-1992$ & 36 & 12 & 22 & 7 & 1 & 1 \\
\hline $1993-1994$ & 17 & 11 & 13 & 9 & 2 & 2 \\
\hline $1995-1996$ & 23 & 4 & 9 & 6 & 0 & 0 \\
\hline $1997-1998$ & 56 & 24 & 15 & 9 & 2 & 2 \\
\hline $1999-2000$ & 57 & 22 & 16 & 10 & 2 & 2 \\
\hline $2001-2002$ & 88 & 38 & 23 & 15 & 2 & 2 \\
\hline $2003-2004$ & 113 & 45 & 37 & 22 & 2 & 1 \\
\hline $2005-2006$ & 203 & 88 & 48 & 29 & 3 & 3 \\
\hline $2007-2008$ & 335 & 115 & 100 & 40 & 4 & 3 \\
\hline $2009-2010$ & 441 & 129 & 111 & 53 & 1 & 1 \\
\hline $2011-2012$ & 656 & 197 & 122 & 38 & 5 & 2 \\
\hline $2013-2014$ & 807 & 213 & 138 & 21 & 4 & 2 \\
\hline $2015-2016$ & 871 & 76 & 147 & 14 & 8 & 3 \\
\hline
\end{tabular}

Fonte: Elaborado pelos autores.

O conjunto de resultados, reunido e apresentado em oito tabelas e três figuras, permite uma série de análises e discussões acerca do campo de Turismo no Brasil. Chama a atenção o crescimento vertiginoso do número de artigos publicados e da entrada de novos autores e instituições ao longo dos anos 2000 e 2010 (Tabela 1). Cabe destacar que, nos anos 2000, seis dos 14 periódicos foram criados.

Tabela 3 - Distribuição de atores por número de artigos publicados

\begin{tabular}{lrrrrrr}
\multirow{2}{*}{ Quantidade } & \multicolumn{2}{c}{ Autores } & \multicolumn{2}{c}{ Instituições } & \multicolumn{2}{c}{ Países } \\
\cline { 2 - 8 } & Número & \% do total & Número & \% do total & Número & \% do total \\
\hline 1 artigo & 2.732 & $73,54 \%$ & 509 & $63,31 \%$ & 12 & $31,58 \%$ \\
\hline 2 artigos & 539 & $14,51 \%$ & 97 & $12,06 \%$ & 6 & $15,79 \%$ \\
\hline 3 artigos & 195 & $5,25 \%$ & 35 & $4,35 \%$ & 2 & $5,26 \%$ \\
\hline 4 artigos & 91 & $2,45 \%$ & 28 & $3,48 \%$ & 2 & $5,26 \%$ \\
\hline 5 artigos & 44 & $1,18 \%$ & 17 & $2,11 \%$ & 1 & $2,63 \%$ \\
\hline 6 artigos & 31 & $0,83 \%$ & 9 & $1,12 \%$ & 3 & $7,89 \%$ \\
\hline 7 ou mais & 83 & $2,23 \%$ & 109 & $13,56 \%$ & 12 & $31,58 \%$ \\
\hline
\end{tabular}

Fonte: Elaborado pelos autores. 
Padrão de colaboração e coautoria no campo de turismo: análises bibliométricas e de redes em 14 periódicos científicos brasileiros (1990-2016)

André Fontan Köhler, Luciano Antonio Digiampietri e Gabriela Sarro de Almeida

Tabela 4 - Distribuição de atores por número de colaborações (coautorias)

\begin{tabular}{lrrrrrrr}
\multirow{2}{*}{ Quantidade } & \multicolumn{2}{c}{ Autores } & \multicolumn{2}{c}{ Instituições } & \multicolumn{2}{c}{ Países } \\
\cline { 2 - 8 } & Número & \% do total & Número & \% do total & Número & \% do total \\
\hline Sem colaboração & 420 & $11,31 \%$ & 216 & $26,87 \%$ & 5 & $13,16 \%$ \\
\hline 1 colaborador & 1089 & $29,31 \%$ & 282 & $35,07 \%$ & 15 & $39,47 \%$ \\
\hline 2 colaboradores & 1044 & $28,10 \%$ & 132 & $16,42 \%$ & 6 & $15,79 \%$ \\
\hline 3 colaboradores & 505 & $13,59 \%$ & 36 & $4,48 \%$ & 4 & $10,53 \%$ \\
\hline 4 colaboradores & 298 & $8,02 \%$ & 32 & $3,98 \%$ & 4 & $10,53 \%$ \\
\hline 5 colaboradores & 143 & $3,85 \%$ & 25 & $3,11 \%$ & 2 & $5,26 \%$ \\
\hline 6 colaboradores & 71 & $1,91 \%$ & 14 & $1,74 \%$ & 0 & $0,00 \%$ \\
\hline 7 ou mais & 145 & $3,90 \%$ & 67 & $8,33 \%$ & 2 & $5,26 \%$ \\
\hline
\end{tabular}

Fonte: Elaborado pelos autores.

Tabela 5 - Concentração da produção, por ator, no período 1990-2016

Número de atores

Autores Instituições Países

\begin{tabular}{llrrr}
\hline Primeiro centil (1\%) & Número de artigos & 520 & 944 & 2.387 \\
\cline { 2 - 5 }$\%$ de artigos & $17,99 \%$ & $34,64 \%$ & $87,60 \%$ \\
\hline \multirow{2}{*}{ Primeiro decil (10\%) } & Número de artigos & 1.690 & 2.125 & 2.591 \\
\cline { 2 - 5 } \% de artigos & $58,48 \%$ & $77,98 \%$ & $95,08 \%$ \\
\hline Primeiro quartil & Número de artigos & 2.397 & 2.474 & 2.688 \\
\cline { 2 - 5 } & \% de artigos & $82,94 \%$ & $90,79 \%$ & $98,64 \%$ \\
\hline
\end{tabular}

Fonte: Elaborado pelos autores.

As Figuras 1 e 2 mostram extensas redes de autores (redes de coautoria com centenas de indivíduos) e esparsas redes de instituições (redes com densidade inferior a 0,05) . A adição de novos autores e instituições (Tabela 2) acelerou-se a partir dos biênios 2005-2006 (autores) e 2007-2008 (instituições). Em extensão, o crescimento é mais perceptível na rede de autores, na qual tem havido o contínuo crescimento da média dos caminhos geodésicos - mais pronunciada desde 2012 - e do diâmetro do grafo (Tabela 7).

Na rede de instituições, essas duas métricas cresceram ao longo dos anos 1990 e 2000, para diminuírem na década corrente. Apesar de terem entrado mais de 400 instituições nos anos 2010, o aumento da colaboração entre nós, antes distantes, fez a rede tornar-se mais compacta.

No caso do nível de capilaridade e interconexão da rede, alguns pontos chamam a atenção. A maior parte dos autores $(68,71 \%)$ e instituições $(78,36 \%)$ tem duas ou menos colaborações (Tabela 4). Contudo, a média, moda e mediana de coautorias - autores e instituições - têm crescido, desde os anos 2000 (Tabela $6)$. 
Desde 2011, a mediana das colaborações por autor é dois, por mais que a moda tenha continuado igual a um. Em 2016, a média foi igual a 2,3. Isso aponta o avanço da pesquisa e produção em rede, inclusive entre autores de diferentes instituições e entre orientadores e orientandos, e a diminuição (proporcional) dos trabalhos assinados por apenas um autor. A mesma tendência de aumento das colaborações pode ser vista na rede de instituições.

Na métrica "Porcentagem de nós no componente gigante", percebem-se aumentos para autores (desde 2012) e instituições (desde 2006), mas com números muito diferentes. Em 2016, a métrica foi igual a 26,08\% para autores, quase o triplo do registrado em 2012. Mesmo assim, a Figura 1 mostra como a rede de autores é dispersa, já que, a grosso modo, três a cada quatro autores não estão no componente gigante. Para além dele, não há nenhum outro componente conexo relevante em número de nós. Multiplicam-se pequenos componentes conexos, nos quais poucos nós colaboram entre si, apesar de existirem alguns autores muito produtivos fora do componente gigante.

Nas instituições, a métrica registra crescimento no período 2000-2014, e está com 60,70\% (2016), o que torna a rede mais compacta do que a de autores. Fora do componente gigante, não há nenhuma instituição muito produtiva, ao contrário do que se verifica na rede de autores. 


\section{Cenestatio}

a colaboração e coautoria no campo de turismo: análises bibliométricas e de redes em 14 periódicos científicos brasileiros (1990-2016)

André Fontan Köhler, Luciano Antonio Digiampietri e Gabriela Sarro de Almeida

Tabela 6 - Quantidade de artigos publicados e de colaborações (coautorias), por ator Autores

\begin{tabular}{|c|c|c|c|c|c|c|c|c|c|c|c|c|c|c|c|c|c|c|}
\hline \multirow[t]{2}{*}{ Ano } & \multicolumn{3}{|c|}{ Artigos publicados } & \multicolumn{3}{|c|}{ Colaborações } & \multicolumn{3}{|c|}{ Artigos publicados } & \multicolumn{3}{|c|}{ Colaborações } & \multicolumn{3}{|c|}{ Artigos publicados } & \multicolumn{3}{|c|}{ Colaborações } \\
\hline & Média & Mediana & Moda & Media & Mediana & Moda & Média & Mediana & Moda & Media & Mediana & Moda & Média & Mediana & Moda & Media & Mediana & $\overline{\text { Moda }}$ \\
\hline 1990 & 1,00 & 1 & 1 & 0,17 & 0 & 0 & 3,00 & 1 & 1 & 0,00 & 0 & 0 & 5,50 & 5,5 & 1 & 0,00 & 0 & $\overline{0}$ \\
\hline 1991 & 1,06 & 1 & 1 & 0,26 & 0 & 0 & 2,00 & 1 & 1 & 0,14 & 0 & 0 & 14,50 & 14,5 & 1 & 0,00 & 0 & 0 \\
\hline 1992 & 1,23 & 1 & 1 & 0,33 & 0 & 0 & 2,04 & 1 & 1 & 0,16 & 0 & 0 & 17,33 & 1 & 1 & 0,00 & 0 & 0 \\
\hline 1993 & 1,37 & 1 & 1 & 0,35 & 0 & 0 & 2,19 & 1 & 1 & 0,13 & 0 & 0 & 22,67 & 1 & 1 & 0,00 & 0 & $\frac{0}{2}$ \\
\hline 1994 & 1,40 & 1 & 1 & 0,31 & 0 & 0 & 2,13 & 1 & 1 & 0,11 & 0 & 0 & 16,20 & 1 & 1 & 0,00 & 0 & 0 \\
\hline 1995 & 1,49 & 1 & 1 & 0,33 & 0 & 0 & 2,29 & 1 & 1 & 0,10 & 0 & 0 & 19,00 & 1 & 1 & 0,00 & 0 & $\overline{0}$ \\
\hline 1996 & 1,52 & 1 & 1 & 0,55 & 0 & 0 & 2,36 & 1 & 1 & 0,17 & 0 & 0 & 22,00 & 1 & 1 & 0,00 & 0 & 0 \\
\hline 1998 & 1,40 & 1 & 1 & 1,28 & 0 & 0 & 2,58 & 1 & 1 & 0,29 & 0 & 0 & 22,00 & 2 & 1 & 0,00 & 0 & 0 \\
\hline 1999 & 1,41 & 1 & 1 & 1,22 & 0 & 0 & 2,72 & 1 & 1 & 0,30 & 0 & 0 & 21,88 & 1,5 & 1 & 0,00 & 0 & 0 \\
\hline 2000 & 1,44 & 1 & 1 & 1,18 & 0 & 0 & 2,79 & 1 & 1 & 0,33 & 0 & 0 & 23,11 & 1 & 1 & 0,22 & 0 & 0 \\
\hline 2001 & 1,43 & 1 & 1 & 1,17 & 0 & 0 & 2,83 & 1 & 1 & 0,46 & 0 & 0 & 25,44 & 2 & 1 & 0,22 & 0 & 0 \\
\hline 2002 & 1,45 & 1 & 1 & 1,49 & 1 & 0 & 2,84 & 1 & 1 & 0,59 & 0 & 0 & 24,00 & 2 & 1 & 0,73 & 0 & 0 \\
\hline 2003 & 1,50 & 1 & 1 & 1,52 & 1 & 0 & 2,93 & 1 & 1 & 0,63 & 0 & 0 & 27,82 & 2 & 1 & 0,73 & 0 & 0 \\
\hline 2004 & 1,48 & 1 & 1 & 1,54 & 1 & 0 & 2,83 & 1 & 1 & 0,67 & 0 & 0 & 27,00 & 2 & 1 & 0,92 & 0 & $\overline{0}$ \\
\hline 2005 & 1,48 & 1 & 1 & 1,56 & 1 & 0 & 3,00 & 1 & 1 & 0,74 & 0 & 0 & 28,93 & 2 & 1 & 1,00 & 0,5 & 0 \\
\hline 2008 & 1,43 & 1 & 1 & 1,67 & 1 & 1 & 3,00 & 1 & 1 & 1,17 & 1 & 0 & 35,75 & 3 & 1 & 1,10 & 0,5 & 0 \\
\hline 2009 & 1,44 & 1 & 1 & 1,73 & 1 & 1 & 3,09 & 1 & 1 & 1,30 & 1 & 0 & 40,38 & 3 & 1 & 1,14 & 1 & 0 \\
\hline 2010 & 1,44 & 1 & 1 & 1,83 & 1 & 1 & 3,18 & 1 & 1 & 1,48 & 1 & 0 & 47,95 & 3 & 1 & 1,24 & 1 & 0 \\
\hline 2011 & 1,47 & 1 & 1 & 1,94 & 2 & 1 & 3,42 & 1 & 1 & 1,71 & 1 & 0 & 55,36 & 3 & 1 & 1,36 & 1 & 0 \\
\hline 2012 & 1,49 & 1 & 1 & 2,01 & 2 & 1 & 3,71 & 1 & 1 & 1,91 & 1 & 1 & 57,00 & 2 & 1 & 1,77 & 1 & 1 \\
\hline 2013 & 1,52 & 1 & 1 & 2,07 & 2 & 1 & 3,94 & 1 & 1 & 2,09 & 1 & 1 & 66,74 & 3 & 1 & 2,00 & 1 & 1 \\
\hline 2014 & 1,56 & 1 & 1 & 2,16 & 2 & 1 & 4,23 & 1 & 1 & 2,17 & 1 & 1 & 70,90 & 2 & 1 & 2,13 & 1 & 1 \\
\hline 2015 & 1,60 & 1 & 1 & 2,22 & 2 & 1 & 4,45 & 1 & 1 & 2,31 & 1 & 1 & 68,94 & 2,5 & 1 & 2,11 & 1 & 1 \\
\hline 2016 & 1,63 & 1 & 1 & 2,30 & 2 & 1 & 4,67 & 1 & 1 & 2,42 & 1 & 1 & 74,68 & 3 & 1 & 2,53 & 1 & 1 \\
\hline
\end{tabular}

Fonte: Elaborado pelos autores. 
Padrão de colaboração e coautoria no campo de turismo: análises bibliométricas e de redes em 14 periódicos científicos brasileiros (1990-2016)

André Fontan Köhler, Luciano Antonio Digiampietri e Gabriela Sarro de Almeida

Tabela 7 - Conjunto de métricas e medidas de redes para autores, instituições e países

\begin{tabular}{|c|c|c|c|c|c|c|c|c|c|c|c|c|c|c|c|}
\hline MÉTRICAS E MEDIDAS & Ator & 1990 & 1992 & 1994 & 1996 & 1998 & 2000 & 2002 & 2004 & 2006 & 2008 & 2010 & 2012 & 2014 & 2016 \\
\hline \multirow{3}{*}{ Grau médio da rede } & Autor & 0,16667 & 0,33333 & 0,30769 & 0,54545 & 1,27778 & 1,18408 & 1,48789 & 1,54229 & 1,54711 & 1,67234 & 1,83345 & 2,01473 & 2,15612 & 2,3004 \\
\hline & Instituição & 0 & 0,16 & 0,10526 & 0,17021 & 0,29032 & 0,33333 & 0,59406 & 0,66667 & 0,88172 & 1,17483 & 1,47607 & 1,90751 & 2,17352 & 2,4204 \\
\hline & País & 0 & 0 & 0 & 0 & 0 & 0,22222 & 0,72727 & 0,92308 & 1,125 & 1,1 & 1,2381 & 1,76923 & 2,13333 & 2,52632 \\
\hline \multirow{3}{*}{ Média dos caminhos geodésicos } & Autor & 1 & 1 & 1 & 1,24138 & 1,07217 & 1,84434 & 2,10707 & 2,42481 & 2,43785 & 2,49907 & 3,11183 & 4,98968 & 8,127 & 9,72506 \\
\hline & Instituição & - & 1 & 1 & 1,2 & 1,30769 & 1,45833 & 1,70455 & 1,89326 & 3,1868 & 5,40781 & 4,39534 & 4,06462 & 4,04535 & 3,84579 \\
\hline & País & - & - & - & - & - & 1 & 1,33333 & 1,6 & 1,67857 & 1,88889 & 1,89091 & 2,22222 & 2,11594 & 2,41631 \\
\hline \multirow{3}{*}{$\begin{array}{l}\text { Porcentagem de nós no } \\
\text { componente gigante }\end{array}$} & Autor & $16,67 \%$ & $6,25 \%$ & $4,62 \%$ & $5,68 \%$ & $7,64 \%$ & $8,96 \%$ & $8,65 \%$ & $8,71 \%$ & $6,78 \%$ & $5,43 \%$ & $6,30 \%$ & $9,57 \%$ & $16,28 \%$ & $26,08 \%$ \\
\hline & Instituição & $33,33 \%$ & $8,00 \%$ & $5,26 \%$ & $6,38 \%$ & $6,45 \%$ & $7,69 \%$ & $10,89 \%$ & $9,42 \%$ & $20,43 \%$ & $35,66 \%$ & $47,61 \%$ & $56,84 \%$ & $61,19 \%$ & $60,70 \%$ \\
\hline & País & $50,00 \%$ & $33,33 \%$ & $20,00 \%$ & $20,00 \%$ & $14,29 \%$ & $22,22 \%$ & $36,36 \%$ & $46,15 \%$ & $50,00 \%$ & $50,00 \%$ & $52,38 \%$ & $69,23 \%$ & $80,00 \%$ & $81,58 \%$ \\
\hline \multirow{3}{*}{ Diâmetro do grafo } & Autor & 1 & 1 & 1 & 3 & 3 & 5 & 5 & 6 & 6 & 6 & 8 & 15 & 24 & 29 \\
\hline & Instituição & - & 1 & 1 & 2 & 2 & 2 & 3 & 4 & 6 & 12 & 10 & 9 & 8 & 9 \\
\hline & $\overline{\text { País }}$ & - & - & - & - & - & 1 & 2 & 2 & 2 & 3 & 3 & 4 & 3 & 5 \\
\hline \multirow{3}{*}{ Densidade da rede } & Autor & 0,01515 & 0,00709 & 0,00481 & 0,00627 & 0,00894 & 0,00592 & 0,00517 & 0,00385 & 0,00256 & 0,00178 & 0,00133 & 0,00099 & 0,00076 & 0,00062 \\
\hline & Instituição & 0 & 0,00667 & 0,00284 & 0,0037 & 0,00476 & 0,00433 & 0,00594 & 0,00487 & 0,00477 & 0,00412 & 0,00373 & 0,00368 & 0,00331 & 0,00301 \\
\hline & País & 0 & 0 & 0 & 0 & 0 & 0,02778 & 0,07273 & 0,07692 & 0,075 & 0,05789 & 0,0619 & 0,07077 & 0,07356 & 0,06828 \\
\hline \multirow{3}{*}{ Coeficiente de aglomeração } & Autor & - & 1 & 1 & 0,83333 & 0,99422 & 0,90556 & 0,84965 & 0,80832 & 0,74946 & 0,69122 & 0,65057 & 0,55908 & 0,49381 & 0,43632 \\
\hline & Instituição & - & - & - & 0 & 0 & 0 & 0,1 & 0,0531 & 0,0625 & 0,12086 & 0,10839 & 0,10472 & 0,10466 & 0,10736 \\
\hline & $\overline{\text { País }}$ & - & - & - & - & - & - & 0,6 & 0,25 & 0,23077 & 0,17143 & 0,19565 & 0,16071 & 0,09589 & 0,16612 \\
\hline \multirow{3}{*}{ Assortatividade de grau } & Autor & - & 1 & 1 & 0,73333 & 0,99871 & 0,91542 & 0,86921 & 0,80254 & 0,74059 & 0,58483 & 0,43671 & 0,19119 & 0,10215 & 0,06119 \\
\hline & Instituição & - & - & - & $-0,33333$ & $-0,34043$ & $-0,29369$ & $-0,29773$ & $-0,32959$ & $-0,23777$ & $-0,1774$ & $-0,13603$ & $-0,13337$ & $-0,13426$ & $-0,11049$ \\
\hline & País & - & - & - & - & - & - & $-0,71429$ & $-0,83333$ & $-0,8$ & $-0,72067$ & $-0,67093$ & $-0,59671$ & $-0,67373$ & $-0,46817$ \\
\hline Assortatividade de instituição & Autor & 1 & 0,42857 & 0,4 & 0,42857 & 0,74713 & 0,70175 & 0,54455 & 0,4 & 0,32553 & 0,20674 & 0,15672 & 0,08852 & 0,09923 & 0,0976 \\
\hline \multirow{3}{*}{ Centralização de grau } & Autor & 0,07576 & 0,03546 & 0,02644 & 0,02821 & 0,06099 & 0,05408 & 0,0365 & 0,02608 & 0,01731 & 0,01206 & 0,00954 & 0,00834 & 0,01085 & 0,01096 \\
\hline & Instituição & - & 0,035 & 0,02418 & 0,03978 & 0,04442 & 0,06061 & 0,09406 & 0,08273 & 0,08172 & 0,07307 & 0,07961 & 0,07933 & 0,07291 & 0,06672 \\
\hline & País & - & - & - & - & - & 0,09722 & 0,22727 & 0,33974 & 0,39167 & 0,36316 & 0,3881 & 0,44923 & 0,54713 & 0,47226 \\
\hline \multirow{3}{*}{ Centralização de proximidade } & Autor & 0,01446 & 0,00156 & 0,00085 & 0,00092 & 0,00091 & 0,00081 & 0,00054 & 0,0004 & 0,00021 & 0,00011 & $8,6 \mathrm{E}-05$ & $9,1 \mathrm{E}-05$ & 0,00011 & 0,00014 \\
\hline & Instituição & - & 0,00298 & 0,00133 & 0,00175 & 0,00145 & 0,00158 & 0,00184 & 0,0011 & 0,00207 & 0,00244 & 0,00238 & 0,00218 & 0,00186 & 0,00151 \\
\hline & País & - & 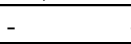 & - & - & 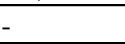 & 0,02604 & 0,05167 & 0,06257 & 0,05785 & 0,04693 & 0,04752 & 0,056 & 0,0657 & 0,05488 \\
\hline \multirow{3}{*}{ Centralização de intermediação } & Autor & 0 & 0 & 0 & 0,00106 & 0,00039 & 0,00319 & 0,00454 & 0,00538 & 0,00342 & 0,00223 & 0,00283 & 0,00639 & 0,01209 & 0,02712 \\
\hline & Instituição & - & 0 & 0 & 0,00097 & 0,00163 & 0,00341 & 0,00885 & 0,0069 & 0,02845 & 0,05191 & 0,12648 & 0,12547 & 0,13213 & 0,10537 \\
\hline & País & - & - & - & - & - & 0 & 0,04444 & 0,13636 & 0,17587 & 0,17852 & 0,19987 & 0,32867 & 0,47197 & 0,50601 \\
\hline
\end{tabular}

Fonte: Elaborado pelos autores. 
Padrão de colaboração e coautoria no campo de turismo: análises bibliométricas e de redes em 14 periódicos científicos brasileiros (1990-2016)

André Fontan Köhler, Luciano Antonio Digiampietri e Gabriela Sarro de Almeida

Autores

Tabela 8 - Métricas locais de centralidade por autores, instituições e países (1990-2016)

\begin{tabular}{|c|c|c|c|c|c|c|c|c|c|c|}
\hline Autores & C. de grau & Classificação & C. de intermediação & Classificação & C. de proximidade & Classificação & Page Rank & Classificação & Número de artigos & Classificação \\
\hline Alexandre Panosso Netto & 13 & 27 & 0,01274668 & 9 & $9,79544 \mathrm{E}-08$ & 138 & 30,000919763 & 37 & 7 & 67 \\
\hline André Riani Costa Perinotto & 18 & 9 & $2,49455 \mathrm{E}-05$ & 288 & $7,28691 \mathrm{E}-08$ & 1.107 & 0,001718089 & 7 & 16 & 10 \\
\hline Carlos Alberto Cioce Sampaio & 26 & 2 & 0,00343131 & 53 & $9,79425 \mathrm{E}-08$ & 476 & 0,001928441 & 3 & 23 & \\
\hline Diogo Luders Fernandes & 8 & 102 & 0,009303102 & 15 & $9,79638 \mathrm{E}-08$ & 7 & 0,000538728 & 148 & 4 & 159 \\
\hline Doris van de Meene Ruschmann & 20 & 5 & 0,01590207 & 6 & $9,79654 \mathrm{E}-08$ & 3 & 0,001395999 & 11 & 20 & j \\
\hline Edilene Adelino Pequeno & 7 & 119 & 0,01500383 & 8 & $9,79288 \mathrm{E}-08$ & 696 & 0,000587483 & 112 & 4 & 159 \\
\hline Elizabete Sayuri Kushano & 8 & 93 & 0,01175242 & 10 & $9,79625 \mathrm{E}-08$ & 11 & 0,000571313 & 131 & 6 & 84 \\
\hline Francisco Antonio dos Anjos & 20 & 7 & 0,01579212 & 7 & $9,79675 \mathrm{E}-08$ & 1 & 0,001450485 & 9 & 15 & 12 \\
\hline Glauber Eduardo de Oliveira Santos & 15 & 17 & 0,01625891 & 4 & $9,79596 \mathrm{E}-08$ & 27 & 0,00135392 & 12 & 17 & 7 \\
\hline Ivan Rêgo Aragão & 9 & 71 & 0,01840516 & 2 & $9,79424 \mathrm{E}-08$ & 479 & 0,000900557 & 39 & 11 & 19 \\
\hline Josildete Pereira de Oliveira & 20 & 8 & 0,01089633 & 14 & $9,79651 \mathrm{E}-08$ & 4 & 0,001498527 & 8 & 13 & 15 \\
\hline Khalla Tupinamba Ribeiro & 5 & 295 & 0,0161065 & 5 & $9,79357 \mathrm{E}-08$ & 569 & 0,000440014 & 263 & 2 & 445 \\
\hline Marcos Luiz Filippim & 8 & 103 & 0,004872354 & 37 & $9,79635 \mathrm{E}-08$ & 8 & 0,000513975 & 169 & 3 & 250 \\
\hline Maria de Lourdes de Azevedo Barbosa & 18 & 10 & $5,20181 \mathrm{E}-05$ & 280 & $7,31263 \mathrm{E}-08$ & 1.025 & 0,001402127 & 10 & 12 & 16 \\
\hline Milton Augusto Pasquotto Mariani & 23 & 4 & 0,004258884 & 43 & $9,79532 \mathrm{E}-08$ & 173 & 0,001783253 & 5 & 18 & \\
\hline Mirian Rejowski & 23 & 3 & 0,01671642 & 3 & $9,79629 \mathrm{E}-08$ & 9 & 0,002118276 & 2 & 22 & 4 \\
\hline Paulo dos Santos Pires & 14 & 20 & 0,003071121 & 56 & $9,79627 \mathrm{E}-08$ & 10 & 0,001051484 & 28 & 14 & 14 \\
\hline Rivanda Meira Teixeira & 16 & 12 & 0,00658776 & 28 & $9,79442 \mathrm{E}-08$ & 419 & 0,001737873 & 6 & 26 & \\
\hline Sara Joana Gadotti dos Anjos & 12 & 29 & 0,004120566 & 46 & $9,7964 \mathrm{E}-08$ & 6 & 0,000856103 & 43 & 9 & 39 \\
\hline Silvio Luiz Gonçalves Vianna & 10 & 55 & 0,01102173 & 13 & $9,79649 \mathrm{E}-08$ & 5 & 0,00082108 & 49 & 8 & 8 \\
\hline \multicolumn{11}{|l|}{ Instituições } \\
\hline Universidade do Vale do Itajaí & 46 & 3 & 0,05148039 & 3 & $3,91584 \mathrm{E}-06$ & & 0,017887248 & 3 & 156 & \\
\hline Universidade Federal de Mato Grosso do Sul & 20 & 11 & 0,02031171 & 10 & $3,91603 \mathrm{E}-06$ & 4 & 0,00720803 & 13 & 28 & 28 \\
\hline Universidade Federal de Minas Gerais & 31 & 4 & 0,04281937 & 4 & $3,91621 \mathrm{E}-06$ & 3 & 0,011734848 & 4 & 61 & \\
\hline Universidade Federal do Paraná & 56 & 1 & 0,08612633 & 2 & $3,91733 \mathrm{E}-06$ & 2 & 0,021598515 & 1 & 132 & \\
\hline Universidade Federal do Rio Grande do Norte & 27 & 5 & 0,03321003 & 5 & $3,91495 \mathrm{E}-06$ & 9 & 0,01044387 & 5 & 120 & \\
\hline \multicolumn{11}{|l|}{ Países } \\
\hline$\overline{\text { Brasil }}$ & 20 & 1 & 0,5187688 & 1 & 0,003257329 & 1 & 0,188036199 & 1 & 2.387 & \\
\hline Canadá & 4 & 7 & 0,1561562 & 3 & 0,00304878 & 4 & 0,035026741 & 8 & 4 & 17 \\
\hline Cuba & 5 & 3 & 0,02777778 & 4 & 0,003030303 & 7 & 0,044266491 & 4 & 9 & 10 \\
\hline Espanha & 11 & 2 & 0,1911912 & 2 & 0,003115265 & 2 & 0,104723038 & 2 & 98 & \\
\hline México & 5 & 3 & 0,02665165 & 5 & 0,003067485 & 3 & 0,045198016 & 3 & 75 & \\
\hline
\end{tabular}

Fonte: Elaborado pelos autores. 
Figura 1 - Rede de autores

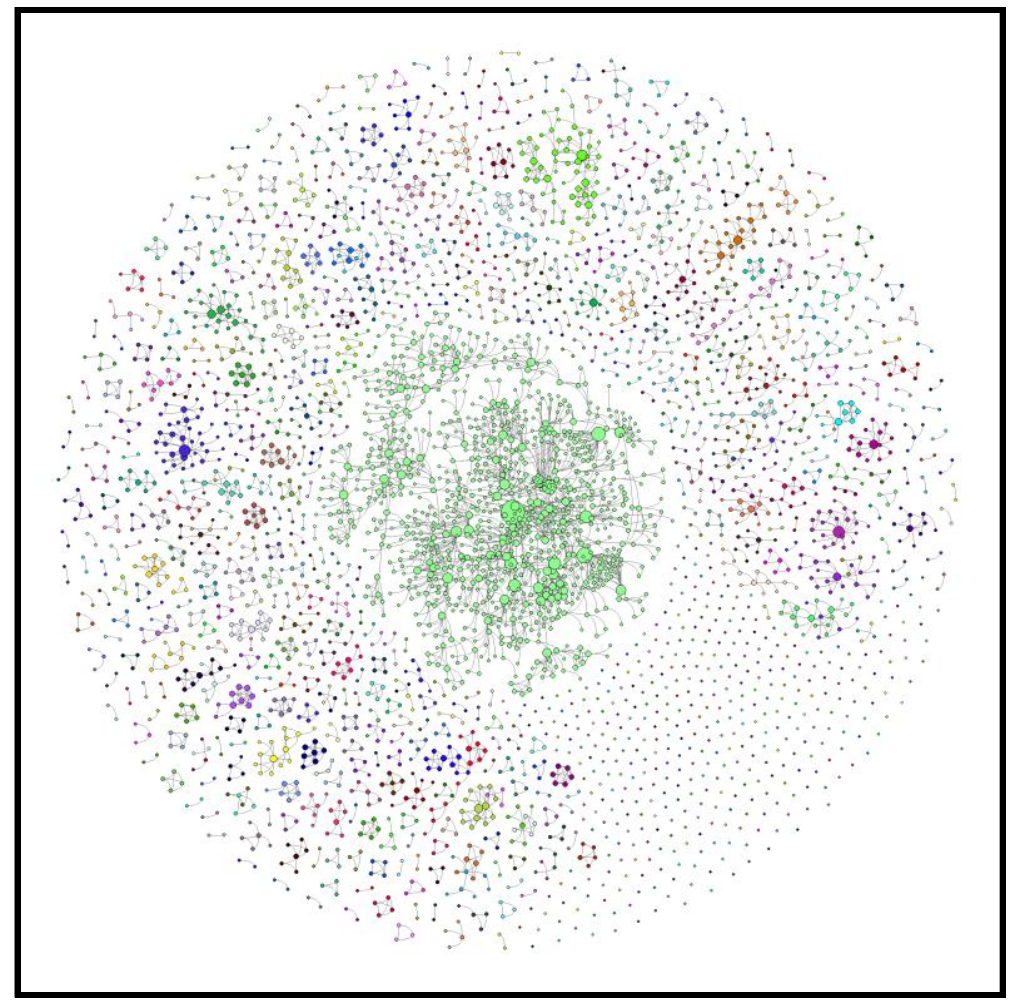

Fonte: Elaborado pelos autores.

O coeficiente de aglomeração é uma métrica-chave para se medir o nível de estabilidade e maturidade da rede, a não ser quando ela seja muito pequena; nesse caso, o coeficiente tende a ser um número alto.

Na rede de autores, o coeficiente segue alto de 1992 a 2000, tendo caído continuamente desde 2002. Em 2016, ele foi igual a 0,4363 (Tabela 7). Contudo, essa trajetória de queda não indica a falta de maturidade da rede, pois tem havido a contínua e crescente adição de novos autores (Tabela 2). A diminuição desse coeficiente indica que os autores não têm colaborado apenas com nós mais próximos, o que levaria a certa endogenia na produção de grupos de pesquisa formais e informais. Isso aumenta a capilaridade e a troca de informações na rede. 
Figura 2 - Rede de instituições

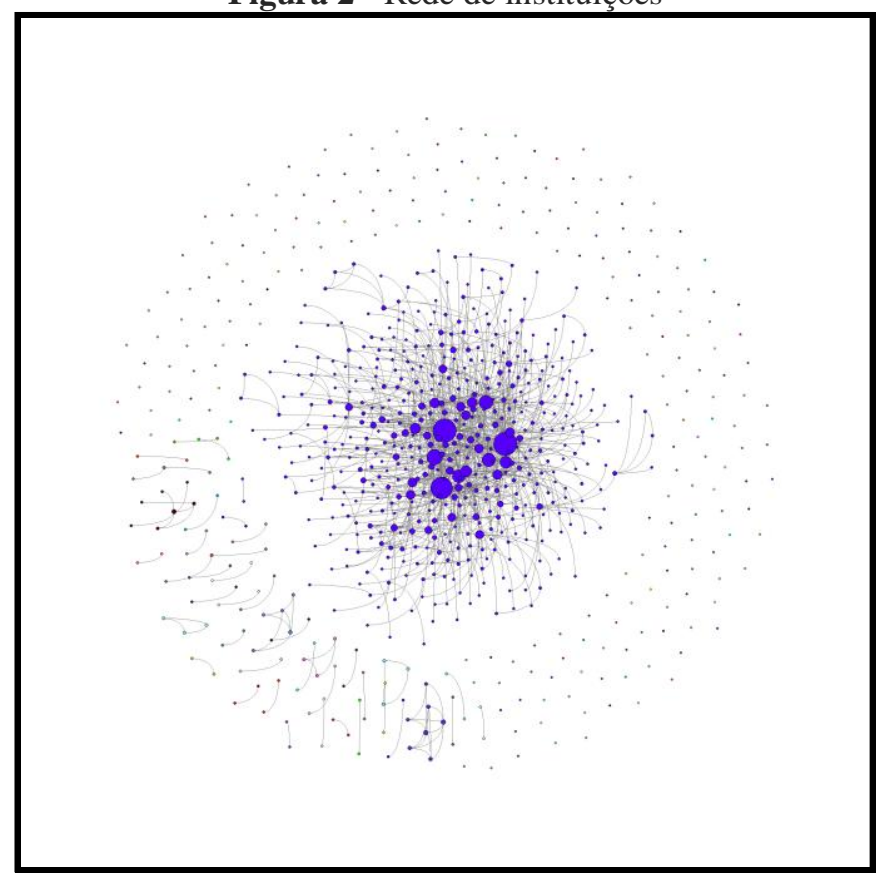

Fonte: Elaborado pelos autores.

Figura 3 - Rede de países

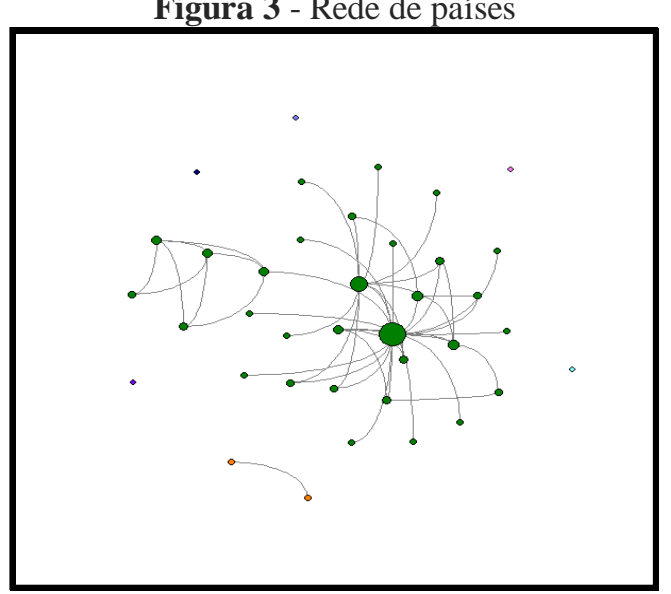

Fonte: Elaborado pelos autores.

No caso das instituições, este valor é igual a zero até o ano 2000, indicando a inexistência de relações transitivas na rede. Isto ocorre porque, até esse ano, todas as colaborações envolvem autores de uma única instituição ou de no máximo duas. Devido a novas colaborações ocorridas a partir de 2002, esta medida oscilou um pouco nos anos seguintes, estabilizando-se, nos anos 2010, em valores próximos a 0,1 .

Esta, relativamente baixa, transitividade das relações é explicada, pois mais de $80 \%$ dos artigos possuem autores brasileiros, sendo a maioria publicada 
exclusivamente por autores brasileiros ou, no máximo, com a contribuição de mais um país. Desta forma, há poucas relações diretas entre dois países que não envolvam o Brasil.

A métrica "Densidade da rede" (Tabela 7) apresenta valores pequenos e em queda - em 2016, 0,006 (autores) e 0,003 (instituições). Dado que as redes de autores e instituições estão em rápida expansão, é de se esperar números baixos para essa métrica, pois, quanto maior é a rede, menor tende a ser sua densidade.

As métricas de centralização (Tabela 7) indicam a robustez ou fragilidade da rede, ao medir o quanto ela depende de seu nó mais central. Para autores e instituições, todas as métricas de centralização são baixas, mostrando a robustez dessas redes. Em 2016, o maior número é o da centralização de intermediação para instituições $(0,1054)$. O número é baixo, apesar de a rede ter instituições com dezenas de colaborações (Tabela 8) - Universidade de São Paulo (USP), Universidade Federal do Paraná (UFPR) e Universidade do Vale do Itajaí (Univali), principalmente.

As medidas de centralidade estão apresentadas na Tabela 8; listam-se os 21 autores, seis instituições e cinco países que, em pelo menos uma das três centralidades, aparecem nas primeiras classificações ${ }^{4}$.

Há quatro autores que estão entre os dez mais bem classificados, para as três centralidades; são eles Doris van de Meene Ruschmann, Francisco Antonio dos Anjos, José Manoel Gonçalves Gândara e Mirian Rejowski. Eles apresentam quatro características em comum, a saber: (a) são professores doutores experientes, que têm publicado nos periódicos selecionados desde pelo menos 2001; (b) produziram muitos artigos e ocupam o topo da classificação do campo (Tabela 8 - última coluna); (c) trabalham em instituições centrais da rede - USP, Univali e UFPR; e (d) contam com extensa rede de colaboração, inclusive com orientandos e ex-orientandos de programas de pós-graduação.

$\mathrm{Na}$ rede de instituições, destacam-se a USP, Univali, UFPR e Universidade Federal de Minas Gerais. Com exceção da última, todas mantêm uma pós-graduação stricto sensu em Turismo, e publicam um dos 14 periódicos 
selecionados. Dos 21 autores listados na Tabela 8, a Univali é a instituição mais presente na atuação profissional - cinco professores no total.

No que tange às métricas de assortatividade, os resultados apontam a diversificação do padrão de colaboração e coautoria do campo de Turismo no Brasil. No caso dos autores, a queda contínua da assortatividade de grau $(0,0612$ em 2016) mostra que o número de coautorias de um determinado autor não afeta significativamente a probabilidade de coautoria entre dois nós quaisquer. A assortatividade de instituição teve trajetória de queda similar; o fato de dois autores serem da mesma instituição não aumenta significativamente a probabilidade de eles colaborarem na publicação de um artigo. Dessa forma, o conjunto de resultados aponta que a coautoria entre autores tem ocorrido entre nós com variadas posições na rede, pertencentes ou não à mesma instituição.

A assortatividade de grau para a rede de instituições apresentou valores negativos por todo o período analisado, indicando haver uma tendência na colaboração entre instituições com diferentes números de colaboradores. Isto se justifica pelo fato de as instituições possuírem um número bastante variado de colaboradores, e de as instituições principais colaborarem com um conjunto grande de instituições, incluindo aquelas com poucas colaborações. Apesar disto, observa-se que, ao longo dos anos, o valor desta medida está se aproximando de zero, indicando uma diminuição nessa tendência.

Por fim, toma-se a Tabela 7, que mede o quanto do total da produção do campo é de responsabilidade dos autores e instituições mais produtivos. Pegando o primeiro decil como referência, tem-se que os 372 autores mais produtivos respondem por 1.690 artigos - 58,48\% do total. No caso das instituições, as 81 mais produtivas publicaram 2.125 artigos, ou 77,98\% do total.

Os dados, métricas e redes de países mostram que o Brasil ocupa uma posição central, muito acima de todos os outros. Não há, inclusive, nenhum autor, nem sequer instituição estrangeira, entre os principais, como pode ser verificado na Tabela 8. Como novidade, a Figura 3 e a Tabela 8 mostram que a Espanha é o segundo país mais produtivo e central da rede, sendo, inclusive, responsável por ligar outros nós ao componente gigante. 


\section{Considerações finais}

No Brasil, o campo de Turismo é marcado pela grande fragmentação, como as figuras 1 e 2 tão bem ilustram. Para isso, concorrem dois pontos. Primeiro, o campo está em plena expansão; os resultados mostram que, nos anos 2010, acelerou-se a adição de novos autores e instituições.

É possível listar os principais fatores responsáveis pelo acelerado crescimento do campo. Primeiro, tem havido a valorização crescente de artigos de periódico em detrimento de outros tipos de produção. Segundo, os autores têm publicado cada vez mais cedo - muitos artigos são assinados por discentes de graduação e pós-graduação ${ }^{5}$.

Terceiro, com a consolidação de programas de pós-graduação stricto sensu em Turismo, tem havido a crescente formação de pesquisadores e professores especialistas no campo. Isso é visível na existência, atualmente, de 11 desses programas, frente a apenas sete em 2008. Por fim, o crescente reconhecimento do campo, o aumento do número de títulos (como mostra a Tabela 1) e sua crescente avaliação no Qualis Capes $^{6}$ levam ao aumento do interesse pela publicação.

Segundo, a exemplo de o que Benckendorff e Zehrer (2013) apontam para os principais periódicos internacionais, o campo, no Brasil, também não conta com uma abordagem teórica unificada. Ele é composto por autores com formações acadêmicas e agendas de pesquisa diversas, o que o torna marcado pela diversidade de contribuições de várias ciências e disciplinas, e a ter parte de sua produção marcada pela multidisciplinaridade e interdisciplinaridade.

Outro ponto muito interessante é a configuração das redes de autores e instituições, que é similar à achada por Racherla e Hu (2010) para os principais periódicos internacionais (autores). No Brasil, essas redes, em seu componente gigante, concentram os nós mais produtivos e centrais' interconectados em uma extensa rede de colaboração. Já na "periferia" da rede, há uma grande quantidade de pequenos componentes conexos e de nós isolados, que, via de regra, têm baixa produção de artigos. 


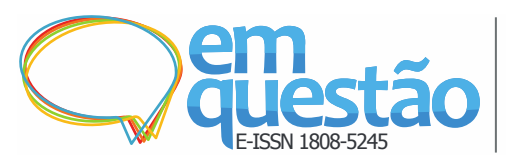

Padrão de colaboração e coautoria no campo de turismo: análises bibliométricas e de redes em 14 periódicos científicos brasileiros (1990-2016)

André Fontan Köhler, Luciano Antonio Digiampietri e Gabriela Sarro de Almeida

\section{Financiamento}

Esse trabalho foi parcialmente financiado pela Universidade de São Paulo, por meio do Programa Unificado de Bolsas de Estudo para Estudantes de Graduação, Edital 2017-2018.

\section{Referências}

BENCKENDORFF, Pierre; ZEHRER, Anita. A network analysis of tourism research. Annals of Tourism Research, Amsterdam, v. 43, n. 1, p. 121-149, 2013.

DIGIAMPIETRI, Luciano Antonio; MENA-CHALCO, Jesús P.; MELO, Pedro O. S. Vaz de; MALHEIRO, Ana P. R.; MEIRA, Dânia N. O.; FRANCO, Laryssa; OLIVEIRA, Leonardo B. BraX-Ray: An x-ray of the Brazilian computer science graduate programs. Plos One, San Francisco, v. 9, n. 4, p. e94541, 2014.

HALL, C. Michael. Publish and perish? Bibliometric analysis, journal ranking and the assessment of research quality in tourism. Tourism Management, Amsterdam, v. 32, n. 1, p. 16-27, 2011.

HOOD, William; WILSON, Concepción. The literature of bibliometrics, scientometrics, and informetrics. Scientometrics, Budapest, v. 52, p. 291-314, 2001.

JOGARATNAM, Giri ; CHON, Kaye; MCCLEARY, Ken; MENA, Miguela; YOO, Joanne. An analysis of institutional contributors to three major academic tourism journals: 1992-2001. Tourism Management, Amsterdam, v. 26, n. 5, p. 641-648, 2005.

KOSEOGLU, Mehmet Ali; RAHIMI, Roya; OKUMUS, Fevzi; LIU, Jingyan. Bibliometric studies in tourism. Annals of Tourism Research, Amsterdam, v. 61, (-), p. 180-198, 2016.

KOVACS, Michelle Helena; BARBOSA, Maria de Lourdes de Azevedo; SOUZA, Anderson Gomes de; MESQUITA, Ana Emília do Prado. Pesquisa em turismo: uma avaliação das metodologias empregadas nos artigos publicados nos anais no triênio do Seminário Anual da Associação Brasileira de Pesquisa e Pós-Graduação em Turismo - ANPTUR. Revista Turismo - Visão e Ação, Balneário Camboriú, v. 14, n. 1, p. 19-34, 2012.

LEMIEUX, Vincent; OUIMET, Mathieu. Análise estrutural das redes sociais. Lisboa: Instituto Piaget, 2008.

MCKERCHER, Bob. A case for ranking tourism journals. Tourism Management, Amsterdam, v. 26, n. 5, p. 649-651, 2005. 
NEWMAN, Mark E. J. The structure and function of complex networks. SIAM Review, Philadelphia, v. 45, n. 2, p. 167-256, 2003.

PAGE, Stephen J. Academic ranking exercises: do they achieve anything meaningful? - a personal view. Tourism Management, Amsterdam, v. 26, n. 5, p. 663-666, 2005.

RACHERLA, Pradeep; HU, Clark. A social network perspective of tourism research collaborations. Annals of Tourism Research, Amsterdam, v. 37, n. 4, p. $1.012-1.034,2010$.

SANTOS, Glauber Eduardo de Oliveira; PANOSSO NETTO, Alexandre; WANG, Xuanyi. Análise de citações de periódicos científicos de turismo no Brasil: subsídios para a estimação de indicadores de impacto. Revista Brasileira de Pesquisa em Turismo, Balneário Camboriú, v. 11, n. 1, p. 61-88, 2017.

SANTOS, Glauber Eduardo de Oliveira; REJOWSKI, Mirian. Comunicação científica em turismo no Brasil: análises descritivas de periódicos nacionais entre 1990 e 2012. Revista Brasileira de Pesquisa em Turismo, Balneário Camboriú, v. 7, n. 1, p. 149-167, 2013.

SCOTT, John. Social network analysis: a handbook. London: SAGE, 2009.

SZWARCFITER, Jayme L. Grafos e algoritmos computacionais. São Paulo: Campus, 1986.

TRIBE, John. The indiscipline of tourism. Annals of Tourism Research, Amsterdam, v. 24, n. 3, p. 638-657, 1997.

TRIBE, John. Tribes, territories and networks in the tourism academy. Annals of Tourism Research, Amsterdam, v. 37, n. 1, p. 7-33, 2010.

WASSERMAN, Stanley; FAUST, Katherine. Social network analysis: methods and applications. Cambridge: Cambridge University Press, 2009.

WANG, Mengyang; CHAI, Lihe. Three new bibliometric indicators/approaches derived from keyword analysis Scientometrics, Budapest, v. 116, p. 721-750, 2018.

ZHAO, Weibing; RITCHIE, J. R. Brent. An investigation of academic leadership in tourism research: 1985-2004. Tourism Management, Amsterdam, v. 28, n. 2, p. 476-490, 2007. 


\title{
Cooperation and coauthorship pattern in the field of tourism: bibliometric and social networks analysis in 14 Brazilian national scientific journals (1990-2016)
}

\begin{abstract}
This article analyses the articles of 14 Brazilian journals about tourism. The objectives are to identify the co-authorship patterns and to verify the importance of actors within the networks. The methodology combines the bibliometric with social networks analysis. The networks of authors and institutions are robust, no longer depending on a central actor. The field is characterized by a great fragmentation, lacking a unified theoretical approach. The networks contain a central group, which concentrates the most central nodes, and a "periphery", composed of small groups with small production.
\end{abstract}

Keywords: Tourism. Scientific journals. Bibliometric and social network analysis.

Recebido: 24/05/2018

Aceito: 02/09/2018

1 As avaliações entre parênteses referem-se às realizadas pelo Comitê de Área Administração Pública e de Empresas, Ciências Contábeis e Turismo.

${ }^{2}$ Neste trabalho, a limpeza de dados consistiu na exclusão de caracteres especiais (isto é, aqueles que não são números, letras ou acentos), bem como a exclusão de espaços em branco, no início ou final de nomes ou títulos. Adicionalmente, ocorreu a verificação automática da presença de todos os artigos em cada um dos volumes das revistas analisadas, com base nas informações de ano, volume e numeração das páginas. Já o processo de resolução de nomes objetivou identificar e unificar as diferentes formas por meio das quais um autor, instituição ou país consta nas informações básicas de cada publicação. A metodologia utilizada é baseada no casamento de nomes, e produz uma lista das diferentes formas que uma entidade é referenciada. Essa lista foi verificada manualmente, para garantir a correta identificação de cada uma das entidades tratadas neste trabalho (autores, instituições e países).

3 Nos artigos, alguns autores aparecem vinculados a duas ou mais instituições, inclusive como docentes. Nesses casos, considerou-se o trabalho em instituição de ensino superior - a primeira a ser mencionada, caso houvesse vínculo com mais de uma.

4 Entre os dez primeiros autores, as cinco primeiras instituições e os três primeiros países, como já foi exposto.

5 Um caso emblemático da coautoria com discentes pode ser observado na produção de José Manoel Gonçalves Gândara, autor com as mais altas centralidades de grau, de intermediação e de Page rank, além de contar com o mais alto número de artigos publicados. Dos 29 artigos publicados, no quadriênio 2013-2016, 20 foram feitos em coautoria com graduandos e pósgraduandos, sob sua orientação. Outros dois foram feitos em coautoria com pós-doutorandos.

6 No triênio 2010-2012, o Sistema Qualis Capes avaliava apenas sete periódicos de Turismo como produção qualificada (A1, A2 e B1), seguindo os critérios do Comitê de Área Administração Pública e de Empresas, Ciências Contábeis e Turismo; cinco revistas internacionais e duas nacionais eram avaliadas como B1. No quadriênio 2013-2016, cinco revistas foram avaliadas como A1, seis como A2 e seis como B1. 